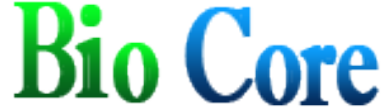

Exploring Scientific Community

\section{International Journal of Nutritional Science and} Food Technology

ISSN 2471-7371

Research Article

Open Access

Multivariate Analysis of Physico-Chemical, Grain Shape and Cooking Quality Parameters of Some

Advance Indica Rice (Oryza Sativa L) Lines Under Irrigated Condition

Muhammad Akhter ${ }^{1}$, Hira Sher ${ }^{1}$, Mohsin Ali Raza ${ }^{1}$, Zulqarnain Haider ${ }^{1}$, Usman Saleem ${ }^{1}$, Rana Ahsen Raza Khan ${ }^{1}$, Abid Mahmood ${ }^{2}$

${ }^{1}$ Rice Research Institute, Kala Shah Kaku, Lahore, Pakistan

${ }^{2}$ Ayub Agricultural Research Institute, Faisalabad, Pakistan

*Corresponding Author: Zulqarnain Haider, Rice Research Institute, Kala Shah Kaku, Lahore, Pakistan Email: z.haider.breeder@ gmail.com

Citation: Zulqarnain Haider(2017) Multivariate analysis of physico-chemical, grain shape and cooking quality parameters of some advance indica rice (Oryza sativa L) lines under irrigated condition. Int J Nutr Sci \& Food Tech 3:2, 53-56

Copyright: (C) Zulqarnain Haider 2017. This is an open-access article distributed under the terms of the Creative Commons Attribution License, which permits unrestricted use, distribution, and reproduction in any medium, provided the original author and source are credited.

Received: August 16, 2017; Accepted: August 30, 2017; Published: September 15, 2017.

\title{
Abstract
}

Rice quality is considered as the 2nd most important trait in rice breeding programs after yield, whereas in some cases as the most important where rice quality is the most valuable trait. Better quality rice gives better returns to the farmer therefore rice lines with better yield as well as supreme quality is very important while breeding for rice crop. In the present study, sixty (60) promising high quality rice lines were evaluated for their grain shape quality traits, cooked grain and physico-chemical traits were studied. Results depicts significantly different behavior of rice genotypes for all the studied quality traits. All the traits showed more than $60 \%$ heritability emphasizing the significant heritable behavior of the genes involved in these traits as well as polygenic behavior of the traits. Average grain length (AGL) showed significantly negative genotypic correlation with average grain length $\left(-0.4158^{*}\right)$ and elongation ratio $\left(-0.3153^{*}\right)$ whereas positive significant genotypic correlation $(0.4143 *)$ with cooked grain lemgth. Average grain thickness had highly significant and positive genotypic correlation $\left(0.8689^{* *}\right)$ with average grain width while elongation ration had highly significant and positive genotypic correlation $\left(0.7118^{* *}\right)$ with cooked grain length.

Keywords: Grain quality traits, physico-chemical traits, rice, genotypic and phenotypic correlation, multivariate analysis.

\section{Introduction}

Rice (Oryza sativa L) is most eatable food across the world. World's round 2/5th (2.4 billion) population uses Rice as staple food. As per IRRI 2009, Rice is leading cereal crop after wheat and feed half of the world. Rice consumers prefers aromatic rice due to its aroma and palatability. Grain quality is very important trait and comes after yield and it is very complex trait and comprises of many important traits such as milling quality, grain size, shape, appearance and other cooking characteristics (Huang et al. 1998; Wan et al. 2004).

Among cereal crops only rice is consumed as whole grain, quality concerns are very important (Hossain et al., 2009). Cooked Grain Length (CGL) is one of the significant cooking quality attributes. Elongation Ratio $(\mathrm{E} / \mathrm{R})$ of rice grain after cooking is desirable feature in high quality like Basmati rice. Because of its linear expansion it fetches premium price. To determine approval of a rice variety kernel shape and visual appearance of rice before and after cooking is very important. Prime rice eating nations have the preference towards varieties that elongate considerably after cooking Khatun et al. (2003).

For high yielding variety approval, rice breeder along with yield give attention to quality parameters which enhance the economic importance of rice. Cooking and processing quality, which can be measured in terms of grain elongation during cooking, amylose content, milling and processing systems also contribute to the economic value of rice. Later, high extent of variability in a population provides the opportunity for selection of varieties having desirable characters. Previous outcomes during the past studies conclude that cooking quality is directly related to the physical and chemical characteristics of the starch present in the endosperm; i.e.; alkali spreading value (ASV) amylose content (AC), gel consistency (GC), (Little et al., 1958., Webb, 1980., Juliano, 1980., Unnevehr et al., 1992., and Tan et al., 1999).

In rice main factor responsible for the grain appearance are grain shape and chalkiness ratio (i.e. the ratio between opaque and translucent grains).Chalky grains process low density of starch granules in contrast to the translucent ones (Del Rosario et al. 1968). Since chalky grains are more likely to break during milling because they are not as hard as the translucent ones (Septiningsih et al. 2003). Head rice is an essential traits for milled rice and main aspect in determining rice market value. (Aluko et al. 2004). 


\section{Material and Methods}

Sixty advance lines were grown in Rice Research Institute Kala Shah Kaku, Pakistan during 2016. Ten randomly selected whole kernel of rice in three sets were taken and length of each grain was measured by placing on a micro scale. Breadth of each grain was measured using a vernier caliper. The average of 10 such observation was taken for final reading of breadth of rice kernels in millimeter $(\mathrm{mm})$. The $\mathrm{L} / \mathrm{B}$ ratio was calculated by dividing the Average length by the average breadth of rice kernel. Based on the L/B ratio, grains were classified into long slender (LS), short slender (SS), medium slender (MS), long bold (LB) and short bold (SB) (Dela Cruz et al., 2000). The length of 10 whole rice kernel after cooking was measured by using the micro scale, and then average length of cooked kernel by the average length of the raw (uncooked) rice (Juliano 1971). Kernal elongation ratio was calculated by dividing the average length of cooked kernel by the average kernel length determined.

Ten cooked rice kernels were selected (intact at both ends) and length of the kernels measured using graph paper for computing the kernel length after cooking (KLAC). ER were calculated (Anonymous, 2004). Select 100 healthy grains. Place in petri dish and soak for $34-40 \mathrm{~min}$ in excess water. Then add these grain for boiling water $\left(100{ }^{\circ} \mathrm{C}\right)$ for $6 \mathrm{~min}$. then drain water and add cold water.

\section{Gelatinization Temperature (GT)}

This was indexed by alkali spreading test [11]. The degree of spreading of individual milled rice kernel in a weak alkali solution $(1.7 \% \mathrm{KOH})$ at room temperature $\left(32 \pm 2^{\circ} \mathrm{C}\right)$ was evaluated on a 7-point numerical scale [12]. Each test was conducted three times, each time, 10 intact milled grains were placed on a petri dish to which $15 \mathrm{ml}$ of $1.7 \% \mathrm{KOH}$ was added. The grains were carefully separated from each other and incubated at $27-30 \mathrm{oC}$ temperature for 23 hours to allow spreading of the grains. Grains swollen to the extent of a cottony center and a cloudy collar were given an alkali spread value (ASV) score 4 and used as check for scoring the rest of the samples in the population. Grains that were un-affected were given ASV of 1 and grains that were dispersed and disappeared completely were given a score of 7. A low ASV correspond to a high gelatinization temperature; con-versely, a high ASV indicates a low GT.

Statistical analysis

All the experiment was carried out using three replications. The data was analyzed by using a staitistical software Statistix v1.8 and PB Tools (IRRI).

\section{Results And Discussion}

Rice consumers' quality criteria is based on appearance, size and shape of the grain. Breeders give more attention to the size of the grain and shape in developing the new rice varieties (Adair et al., 1966). For quality the rice grain can classified into long grain, medium grain and short grain (Adu-kwarteng et al., 2003). The
Basmati lines are categorized into long slender grains with grain length more than $6 \mathrm{~mm}, \mathrm{~L} / \mathrm{B}$ ratio is $3 \mathrm{~mm}$ and high kernel elongation ratio after cooking (Singh et al., 2000). It ranged from 8.74 to 6.86. Maximum grain length was recorded for G37 $(8.74 \mathrm{~mm})$ followed by Line G $60(8.73 \mathrm{~mm})$, Line-G49 $(8.58 \mathrm{~mm})$. Minimum grain length was recorded for G-54 $(6.86 \mathrm{~mm})$, (Table 5). It ranged from 1.67 to 1.32 . Maximum grain width was recorded for G31 (1.67 mm) followed by G23 (1.66 mm), G24 (1.60 mm). Minimum grain width was recorded for G52 $(1.32 \mathrm{~mm}$ ), (Table 5). Grain thickness ranged from $1.2 \mathrm{~mm}$ to $1.5133 \mathrm{~mm}$. Maximum grain thickness is recrded for G54 (1.5133mm) followed by G23 $(1.5 \mathrm{~mm}), \mathrm{G} 25$ and $\mathrm{G} 31(1.47 \mathrm{~mm})$ and minimum grain thickness was recorded in G49 $(1.2 \mathrm{~mm})$ followed byG3 $(1.25 \mathrm{~mm})$ and $\mathrm{G} 2$ $(1.2733 \mathrm{~mm}),($ Tabel 1$)$

\begin{tabular}{|l|l|l|l|l|l|l|l|}
\hline $\begin{array}{l}\text { Quality } \\
\text { trait }\end{array}$ & $\begin{array}{l}\text { Mean } \\
( \pm \text { St. Dev. })\end{array}$ & Max. & Min. & $\begin{array}{l}\text { Mean } \\
\text { Sq. }\end{array}$ & F value & $\operatorname{Pr}(>F)$ & $h^{2}$ \\
\hline AGL & $7.81( \pm 0.69)$ & 8.96 & 6.78 & 0.807 & 2.680 & 0.0000 & 0.63 \\
AGW & $1.525( \pm 0.104)$ & 1.78 & 1.20 & 0.019 & 3.080 & 0.0000 & 0.67 \\
AGT & $1.386( \pm 0.084)$ & 1.55 & 1.10 & 0.013 & 3.622 & 0.0000 & 0.72 \\
CGL & $14.528( \pm 1.255)$ & 17.5 & 11.8 & 3.806 & 7.652 & 0.0000 & 0.87 \\
BP & $4.197( \pm 3.494)$ & 24.3 & 0 & 23.762 & 3.373 & 0.0000 & 0.70 \\
ER & $1.856( \pm 0.159)$ & 2.509 & 1.201 & 0.059 & 5.841 & 0.0000 & 0.83 \\
ASV & $5.759( \pm 1.117)$ & 7 & 3 & 3.300 & 10.822 & 0.0000 & 0.91 \\
\hline
\end{tabular}

Table 1: results of ANOVA for all the studied traits

Results depicts significantly different behavior of rice genotypes for all the studied quality traits. All the traits showed more than $60 \%$ heritability emphasizing the significant heritable behavior of the genes involved in these traits as well as polygenic behavior of the traits. Average grain length (AGL) showed significantly negative genotypic correlation with average grain length $\left(-0.4158^{*}\right)$ and elongation ratio $\left(-0.3153^{*}\right)$ whereas positive significant genotypic correlation $\left(0.4143^{*}\right)$ with cooked grain length. Average grain thickness had highly significant and positive genotypic correlation $\left(0.8689^{* *}\right)$ with average grain width while elongation ration had highly significant and positive genotypic correlation $\left(0.7118^{* *}\right)$ with cooked grain length.

\begin{tabular}{|c|c|c|c|c|c|c|c|}
\hline & & $\begin{array}{r}\text { Avg. } \\
\text { Grain } \\
\text { Lenglh }\end{array}$ & $\begin{array}{r}\text { Avg. } \\
\text { Grain } \\
\text { Width }\end{array}$ & $\begin{array}{l}\text { Avg. Grain } \\
\text { Thickness }\end{array}$ & $\begin{array}{r}\text { Cooked } \\
\text { Grain } \\
\text { Lenglh }\end{array}$ & $\begin{array}{r}\text { Bursting } \\
\text { Percentage }\end{array}$ & $\begin{array}{r}\text { Flongation } \\
\text { Ratio }\end{array}$ \\
\hline \multirow{2}{*}{ Avg. Grain Width } & G & $-0.4158^{*}$ & & & & & \\
\hline & $P$ & -0.2812 & & & & & \\
\hline Avg.Grain & $G$ & -0.2135 & $0.8689 * *$ & & & & \\
\hline Thickness & $P$ & 0.1596 & $0.7932 * *$ & & & & \\
\hline Cooked Grain & G & $0.4143^{*}$ & -0.1948 & -0.1254 & & & \\
\hline Length & $P$ & 0.3667 & -0.2158 & -0.1660 & & & \\
\hline Bursting & G & 0.0219 & 0.1176 & 0.2096 & -0.1932 & & \\
\hline Percentage & $P$ & -0.0076 & 0.1173 & 0.1354 & -0.1644 & & \\
\hline \multirow{2}{*}{ Elongation Ratio } & G & $-0.3153^{*}$ & -0.0402 & -0.0012 & $0.7119 * *$ & -0.1410 & \\
\hline & $P$ & -0.2462 & -0.0776 & -0.0655 & $0.6869 * *$ & -0.1229 & \\
\hline AlkaliSpreading & G & -0.0251 & 0.0280 & 0.0286 & 0.0261 & -0.1345 & -0.0232 \\
\hline Value & $P$ & 0.0002 & -0.0228 & 0.0172 & 0.0293 & -0.1202 & -0.0078 \\
\hline
\end{tabular}

Table 2: Genotypic and phenotypic correlation coefficients among rice grain quality traits 


\section{Cluster SPLOM}

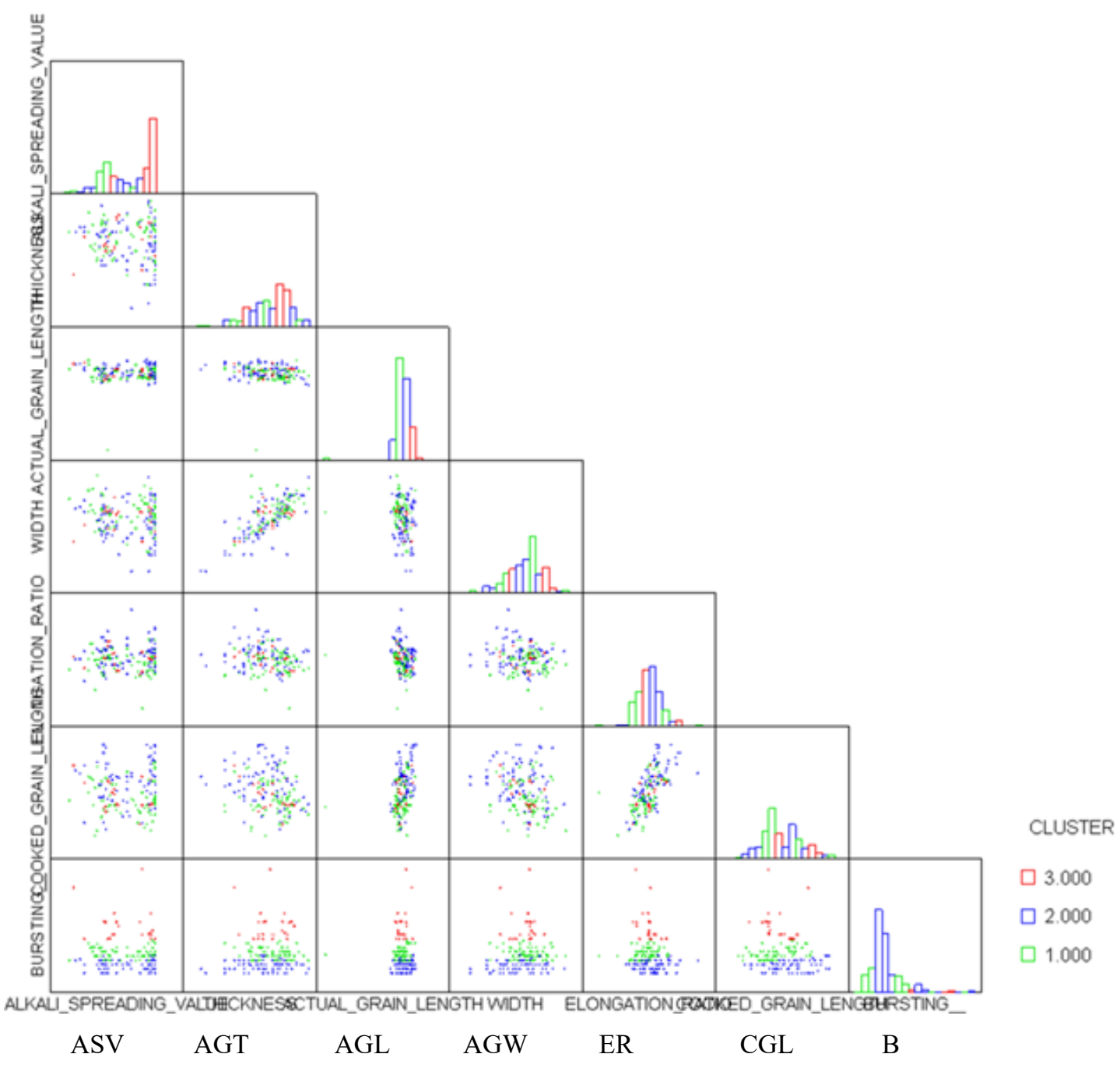

\section{Conclusion}

Rice quality is considered as the 2 nd most important trait in rice breeding programs after yield, whereas in some cases as the most important where rice quality is the most valuable trait. Better quality rice gives better returns to the farmer therefore rice lines with better yield as well as supreme quality is very important while breeding for rice crop. In the present study, sixty (60) promising high quality rice lines were evaluated for their grain shape quality traits, cooked grain and physico-chemical traits were studied. Results depicts significantly different behavior of rice genotypes for all the studied quality traits. All the traits showed more than $60 \%$ heritability emphasizing the significant heritable behavior of the genes involved in these traits as well as polygenic behavior of the traits. Average grain length (AGL) showed significantly negative genotypic correlation with average grain length $\left(-0.4158^{*}\right)$ and elongation ratio $\left(-0.3153^{*}\right)$ whereas positive significant genotypic correlation $\left(0.4143^{*}\right)$ with cooked grain lemgth. Average grain thickness had highly significant and positive genotypic correlation $\left(0.8689^{* *}\right)$ with average grain width while elongation ration had highly significant and positive genotypic correlation $\left(0.7118^{* *}\right)$ with cooked grain length.

References

1. Cruz N D, Khush GS (2000). Rice grain quality evaluation procedures. In: R.K. Singh, U.S. Singh and G.S. Khush, eds., Aromatic rice. Oxford and IBH Publishing Co. Pvt. Ltd., New Delhi, Calcutta, pp. 15-28.

2. Rita B, Sarawgi AK (2008). Agro-morphological and quality characterization of Badshah bhog group from aromatic rice germplasm of Chhattisgarh. Bangladesh Journal of Agriculture Research 33: 479-492.

3. IRRI. 2009. International Rice Research Institute, Manila, the Philippines. Retrieved on 20 September 2010 from http://irri.org/.

4. R.R. Little, G.B. Hilder, and E.H. Dawson,Differential effect of dilute alkali on 25 varieties of milled white rice. Cereal Chemistry $35,1958,111-126$

5. B.O. Juliano and C.G.Pascual, Quality characteristics of milled rice grown in different countries. IRRI Res, 1980. 
6. L.J. Unnevehr, B. Duff, and B.O. Juliano, Consumer demand for rice grain quality. Manila, Philippines: IRRI; 1992. p. 159-174.

7. Hossain M S, Singh AK, Fasih-uz-Zaman (2009). Cooking and eating characteristics of some newly identified inter sub-specific (indica/japonica) rice hybrids. Science Asia 35: 320-325.

8. Sellappan K, Datta K, Parkhi, Datta SK (2009). Rice caryopsis structure in relation to distribution of micronutrients (iron, zinc, $\beta$-carotene) of rice cultivars including transgenic indica rice. Plant Science 177: 557-562.

9. Del Rosario A., Briones V., Vidal A., Juliano B. (1968). Composition and endosperm structure of developing and mature rice kernel. Cereal Chemistry 45, 225-235.

10. Septiningsih E.M., Trijatmiko K.R., Moeljopawiro S., McCouch S.R. (2003). Identification of quantitative trait loci for grain quality in an advance backcross population derived from the Oryza sativa variety IR64 and the wild relative O. rufipogon. Theoretical and Applied Genetics 107, 1433-1441.

11. Aluko G., Martinez C., Tohme J., Castano C., Bergman C., Oard J.H. (2004). QTL mapping of grain quality traits from the interspecific cross Oryza sativa $\times O$. glaberrima. Theoretical and Applied Genetics 109, 630-639.

12. Huang FS, Sun ZX, Hu PS, Tang SQ (1998) Present situations and prospects for the research on rice grain quality forming. Chin J Rice Sci 12(3):172-176

13. Khatun MM, Hazrat Ali M, Quirio D, Cruz ND (2003). Correlation studies on grain physicochemical characteristics of aromatic rice. Pakistan Journal of Biological Science 6(5): 511-513.
14. Wan X-Y, Wan J-M, Su C-C, Wang C-M, Shen W-B, Li J-M, Wang H-L, Jiang L, Liu S-J, Chen L-M, Yasui H, Yoshimura A (2004) QTL detection for eating quality of cooked rice in a population of chromosome segment substitution lines. Theor Appl Genet 110:71-79

15. Adair, C. R., Brachell, H. M., Jodon, N. E., Johnston, T. H., Thysell, J. R., Green, V. E., Webb, B. D. and Atkins J. G. 1966. Rice breeding and testing methods in the U.S. In: U.S. Department of Agriculture Rice in the U.S.: Varieties and Production, 289, p. 19-64. USDA Agriculture Research Survey Handbook.

16. Adu-kwarteng, E., Ellis, W. O., Oduro, I. and Manful, J. T. 2003. Rice grain quality: a comparison of local varieties with new varieties under study in Ghana, Food Control 14(7): 507-514.

17. Singh, R. K., Singh, U. S., Khush, G. S., Rohilla, R., Singh, J. P., Singh, G. and Shekhar, K. S. 2000. Small and Medium Grained Aromatic Rices of India. In Singh, R. K., Singh, U. S. and Khush, G. S. (Eds). Aromatic rices, p. 155-178. New Delhi, Calcutta: Oxford and IBH publishing Co. Pvt. Ltd.

18. Perez, C. M., \& Juliano B. O. (1978). Modification of the simplified amylose test for milled rice. Starch, 30:424-426.

19. Anonymous. (2004). Laboratory Manual on Rice Grain Quality Procedure. Directorate of Rice Research, Rajendranagar, Hyderabad, India, pp. 1-20

20. Dela Cruz N and GS Khush. 2000. Rice grain quality evaluation procedures. In Aromatic rices, (eds. R.K. Singh, U.S. Singh and G.S. Khush), pp.15-28, Publisher, Oxford and IBH publishing Co.Pvt. Ltd., New Delhi, Calcutta. 